\title{
Relevance of HPV Screening for Triaging Equivocal Cytology Findings in the Pap II-p, Pap III and Pap IIID Groups - Results of Two Long-Term Studies
}

\author{
Wertigkeit der HPV-Testung zur Triage unklarer zytologischer Befunde \\ der Gruppen Pap II-p, Pap III und Pap IIID - Ergebnisse zweier Langzeitstudien
}

Authors

Affiliation
A. Luyten, K. U. Petry

Frauenklinik im Klinikum Wolfsburg, Wolfsburg
Key words
- HPV, human papillomavirus
- Pap II-p
- Pap IIID
- triage
Schlüsselwörter
- HPV, human papillomavirus
- Pap II-p
- Pap IIID
- Triage

Deutsche Version unter: www.thieme-connect.de/ ejournals/gebfra revised 19.2.2015

accepted 24.6.2015

\section{Bibliography}

DOI http://dx.doi.org/

10.1055/s-0035-1557841

Geburtsh Frauenheilk 2015; 75: 1058-1062 @ Georg Thieme Verlag KG Stuttgart . New York. ISSN 0016-5751

\section{Correspondence}

Prof. K. U. Petry

Klinikum Wolfsburg

Obstetrics and Gynaecology

Sauerbruchstraße 7

38440 Wolfsburg

k.u.petry@

klinikum.wolfsburg.de

\section{Abstract}

$\nabla$

Introduction: The use of HPV screening for the triage of ASC-US (atypical squamous cells of undetermined significance) cytology results has been established as a sound standard by international trials whereas the data for other cytology findings are in part contradictory. There is a lack of long-term studies on the use of HPV triage in Germany.

Materials and Methods: For the present study data from a primary HPV screening project involving women aged over 30 years, ongoing since 2006, and an epidemiological study on women aged between 20 and 27 years, ongoing since 2009, were used. Upon recruitment, all women underwent a smear test for cytology and screening for "high-risk" HPV using Hybrid Capture 2 (HC2). If both tests were positive or if there were persisting remarkable cytology findings or a positive HPV test, then clarification by colposcopy was performed.

Results: Altogether, among 282 women with Pap II-p (ASC-US), Pap III (ASC-H) or Pap IIID (LSIL + CIN2) and negative HPV test there was no case of CIN3+. Among the women under 30 years of age, however, $69 \%$ (ASC-US) to $85 \%$ (LSIL + CIN2) of the remarkable findings were HPV positive, also among the older women with Pap IIID, the 71\% prevalence of HPV was too high for a triage and even without triage there was a $23 \%$ risk for CIN3+. On the other hand, of the women over 30 years old with ASC-US (Pap II-p) findings, only $21 \%$ were positive for HPV and the risk for CIN3+ in this group was high at $29 \%$. Also for ASC-H (Pap III) findings in the age group of over 30 years with an HPV prevalence of $56 \%$ there was an efficient triage for CIN3+.

Discussion: In summary, the HPV triage of ASCUS (Pap II-p) findings in women aged over 30 years was found to be efficient; in contrast, LSIL +

\section{Zusammenfassung \\ $\nabla$}

Einleitung: Der Einsatz der HPV-Testung zur Triage von ASC-US-(atypical squamous cells of undetermined significance-)Zytologiebefunden ist ein durch internationale Studien gut belegter Standard, für andere zytologische Befunde gibt es teils widersprüchliche Daten. In Deutschland fehlen bisher Langzeitstudien zum Nutzen der HPVTriage.

Material und Methoden: Für die vorliegende Untersuchung wurden Daten eines seit 2006 laufenden primären HPV-Screening-Projekts bei Frauen über 30 Jahren und einer seit 2009 laufenden epidemiologischen Studie bei Frauen zwischen 20 und 27 Jahren genutzt. Bei allen Frauen wurden bei Rekrutierung Abstriche für Zytologie und Testung auf „high-risk“-HPV mittels Hybrid Capture 2 (HC2) entnommen. Fielen beide Tests positiv aus oder persistierten auffällige zytologische Befunde oder ein positiver HPV-Test, dann erfolgte eine Abklärung mittels Kolposkopie.

Ergebnisse: Insgesamt ergab sich bei 282 Frauen mit Pap II-p, Pap III oder Pap IIID und negativem HPV Test kein Fall einer CIN3+. Bei Frauen unter 30 Jahren waren aber 69\% (Pap II-p) bis 85\% (Pap IIID) der auffälligen Befunde HPV-positiv, auch bei älteren Frauen mit Pap IIID ergab sich für eine Triage mit 71\% eine zu hohe HPV-Prävalenz und bereits ohne Triage ein 23\% Risiko für CIN3+. Bei Frauen über 30 Jahren mit Pap-II-p-Befunden waren dagegen nur 21\% HPV-positiv, und das Risiko für CIN3+ war in dieser Gruppe mit 29\% hoch. Auch für Pap-III-Befunde ergab sich in der Altersgruppe über 30 Jahre bei einer HPV-Prävalenz von 56\% für CIN3+ eine effiziente Triage.

Diskussion: Zusammenfassend erwies sich die HPV-Triage von Pap-II-p-Befunden bei Frauen über 30 Jahren als effizient, dagegen erschien bei Pap-IIID-Befunden in dieser Altersgruppe die sofortige Überweisung zur Kolposkopie gerechtfer- 
CIN2 (Pap IIID) findings in this age group justified an immediate referral to colposcopy whereas cytology control appeared to be sufficient for younger women. tigt während bei jüngeren Frauen die zytologische Kontrolle als ausreichend erschien.

\section{Introduction}

\section{$\nabla$}

Cervical cancer arises almost exclusively from an HPV infection persisting for many years to decades that at first leads to premalignant lesions which also may be present for years before a malignant transformation occurs. Beside the option for primary prevention by an HPV vaccination that has been available since 2006 and which can prevent the entire cycle from initial HPV infection to the development of cancer, a very effective secondary prevention has been available for several decades by means of cytological screening by which the genuine cancer precursors (cervical intraepithelial neoplasia grade $3=$ CIN3) are detected and destroyed and consequently the development of cancer can be prevented.

The former Germany cytological nomenclature "München II" classifies unremarkable findings as "Pap I/II", these are summarised together under Pap I in the new "München III" nomenclature. For this the largest group of screening participants an annual routine smear was considered to be sufficient to date. Depending on age structure, remarkable findings occur in about 2.3 to $3.7 \%$ of the participants per screening session [1-3]. A remarkable smear does not imply the diagnosis of an obligate cancer precursor or even cancer. There is international consensus that expert colposcopy. i.e., a colposcopic examination with histological clarification by means of targeted biopsies and/or endocervical curettage or immediate excision carried out by a physician specially trained in colposcopy, is the gold standard for the clarification of remarkable screening findings. The European Federation for Colposcopy (EFC) demands that, prior to excision procedures on the cervix such as, e.g., conisation, a corresponding, obligate colposcopic examination should be undertaken [4]. Decades ago, as the first European country, England set up a network of specialised, state-certified colposcopy clinics and verified their efficiency by means of concomitant studies. Thus, randomised, controlled studies in England not only confirm that unnecessary operations can be avoided by expert colposcopy [5] and that a clarification algorithm with expert colposcopy is cost efficient [6], but also that not all women with low grade cytology findings need be referred to an immediate colposcopy [7]. Since a referral to expert colposcopy can lead to anxiety and stress for the affected women [8], only those women with at least a moderately elevated risk for the presence of CIN3+ (CIN3, ACIS or more) should be referred. Although there is no well validated cut-off value, the necessity for a referral at a risk for CIN3 of more the $20 \%$ is indisputable. In the German health-care routine this would be valid for groups with the finding Pap IV (> 80\% CIN3+) and recurrent Pap IIID (31.4\% CIN3+) [9]. A 20\% cut-off for CIN3+ appears in many countries to be dangerously high from the forensic point of view since, in these cases, a longer-term delay in diagnosis would have to be accepted. Even with the acceptance in many countries of the usual cut-off value of $10 \%$, however, a direct referral of, for example, Pap II-p findings to colposcopy would be excluded. In these cases a triage (clarification diagnostics), i.e., further selection by means of additional tests, should be undertaken. Up to 15 years ago it was standard practice in countries with screening programmes to control even slightly conspicuous findings in the smear test, since then numerous studies have shown a better triage is usually possible in these cases by means of HPV screening. Thus, the triage of slightly conspicuous cytological findings corresponding to the Pap II-p groups by HPV screening is now standard in many European countries; for Germany, however, there is a lack of systematic prospective studies with long-term observations.

The Wolfsburg HPV-Screening Project WOLPHSCREEN (Wolfsburg primary HPV screening project) has been ongoing since 2006 with more than 22000 participants aged over 30 years and the epidemiological study WOLVES (Wolfsburg HPV epidemiological study), ongoing since 2009, with good 1700 women aged from 20-27 years evaluates not only cytological screening findings but also the results of the concomitant HPV screens. The aim of the present study was to clarify the relevance of HPV triage for women of different age groups with Pap II-p, Pap III or Pap IIID in the long term. We defined a priori two criteria for the quality of the HPV triage:

1. By means of HPV triage a low CIN3+ risk of under $10 \%$ for the entire group of findings should increase to more than $10 \%$ in the case of positive findings and/or

2. In order to achieve a significant reduction of referrals to colposcopy, a CIN3+ risk should be excluded with high certainty in the case of negative HPV findings and at least $40 \%$ of the finding groups should exhibit a negative result.

The second item corresponds more or less with the target values of international studies $[10,11]$.

\section{Methods and Patients \\ $\nabla$}

Study design, methods and patient collective of WOLPHSCREEN and WOLVES have been described in detail elsewhere $[2,12]$.

\section{WOLPHSCREEN}

In brief, WOLPHSCREEN is a primary screening project for women over 30 years of age in the Wolfsburg region. All participants underwent a dual testing consisting of cytology and HPV screening for high-risk types (HPV-HR) using the Hybrid Capture 2 (HC2, Qiagen, Hilden, Deutschland). Women with unremarkable findings (inconspicuous cytology and negative HPV test) were subjected to rescreening after 5 years whereas women with conspicuous cytology ( $\geq$ Pap II-p) and positive HPV test were immediately referred to colposcopy irrespective of the severity of the cytological abnormality. Women with abnormal cytological findings and negative HPV status, with the exception of the Pap IV/V groups, received a smear check after (6 and) 12 months. Only those with persisting abnormalities were referred to colposcopy. In cases with only a positive initial HPV test, a further test was performed after 12 months and in cases of persisting HPV with referral to colposcopy.

\section{WOLVES}

In WOLVES the participants in the framework of screening underwent an annual routine cytological smear as well as in the framework of the study an HPV test using HC2 and genotyping by means of LiPA (Innogenetics). Only women with their principal residence in Wolfsburg who were born between $1983 / 84$ or 
$1988 / 89$ or $1993 / 94$ could be enrolled in the study. In the analysis presented here only the data gathered at the first presentation in 2009-2010 of the group born in 1983/84 and the data gathered in 2009-2015 of the group born in 1988/89, again at the first presentation, were evaluated. The ages of the included women were thus between 20 and 27 years. Also WOLVES participants were only directly referred to colposcopy in the case of remarkable cytology and positive HC2 findings, the others underwent monitoring in the offices of the participating physicians.

In both collectives the cytology findings were classified according to München II up to the end of 2013, in 2014 in part and from 2015 a complete change-over to the München III nomenclature occurred. With regard to the current classification, there is some fuzziness for Pap II w findings which include not only Pap II-p but also Pap II-g and especially for Pap IIID findings that are divided into Pap IIID1 and Pap IIID2 in the new nomenclature.

\section{Results}

$\nabla$

\section{WOLPHSCREEN/Pap II-p/g}

Among the WOLPHSCREEN participants $(n=22176)$ a Pap II $w$ (Pap-II-p/-g) finding was seen in $233(1.05 \%$ ) at recruitment (- Fig. 1). 48 of 233 (20.6\%) were HPV-HR positive, of these 48 women 14 suffered from CIN3+ (CIN3+ risk: 29.2\%), whereas among the 185 women with negative $\mathrm{HC} 2$ findings not one case of CIN3+ was diagnosed. In the further course 9 patients were referred to colposcopy on account of persisting abnormal findings, for 8 women controls were lacking, the remaining women showed unremarkable results in the further course. Thus in the case of Pap II w/II-p/-g the HPV tests in women aged over 30 years fulfilled both criteria for a meaningful triage with a reduction in referrals to colposcopy by $79.4 \%$ and a CIN3+ risk for HPV-positive cases of almost $30 \%$ that lies markedly over the cut-off of $10 \%$.

\section{WOLPHSCREEN/Pap III}

Also, among 74 WOLPHSCREEN participants with Pap-III findings (0.33\%) all 22 CIN3+ cases were found in the group of 39 women with positive HC2 findings (CIN3+ risk: $56.4 \%$ ), in contrast, in the further course of the 35 women with negative HC2 findings no case of CIN3+ was seen ( Fig. 2), however, one patient developed endometrial cancer. Altogether 7 and 35 women were referred to colposcopy in the further course due to persisting abnormal findings or a suspicion of glandular neoplasias. Cervical neoplasias were not detected thereby. The courses of the remaining patients were unremarkable with normal cytology findings and negative HPV tests. Thus HPV triage in women over 30 years of age with Pap III findings fulfilled one of the criteria for a meaningful triage with its reduction of referrals to colposcopy by $47.3 \%$.

\section{WOLPHSCREEN/Pap IIID}

168 WOLPHSCREEN participants exhibited Pap IIID findings on recruitment (0.76\%). 120 of these 168 case were HC2-positive (71.4\%), all 38 cases of CIN3+ were found in this group (CIN3+ risk: $31.7 \%$ ). Seven of $48 \mathrm{HC}$-negative women were referred to colposcopy in the further course because of persisting abnormal findings, but no case of CIN3+ was found, the remaining 41 women showed unremarkable cytology and negative HPV test results in the further course ( $\bullet$ Fig. 3). Thus, HPV triage here did not fulfil any of the criteria for a meaningful triage for women over 30 years of age with Pap IIID findings.
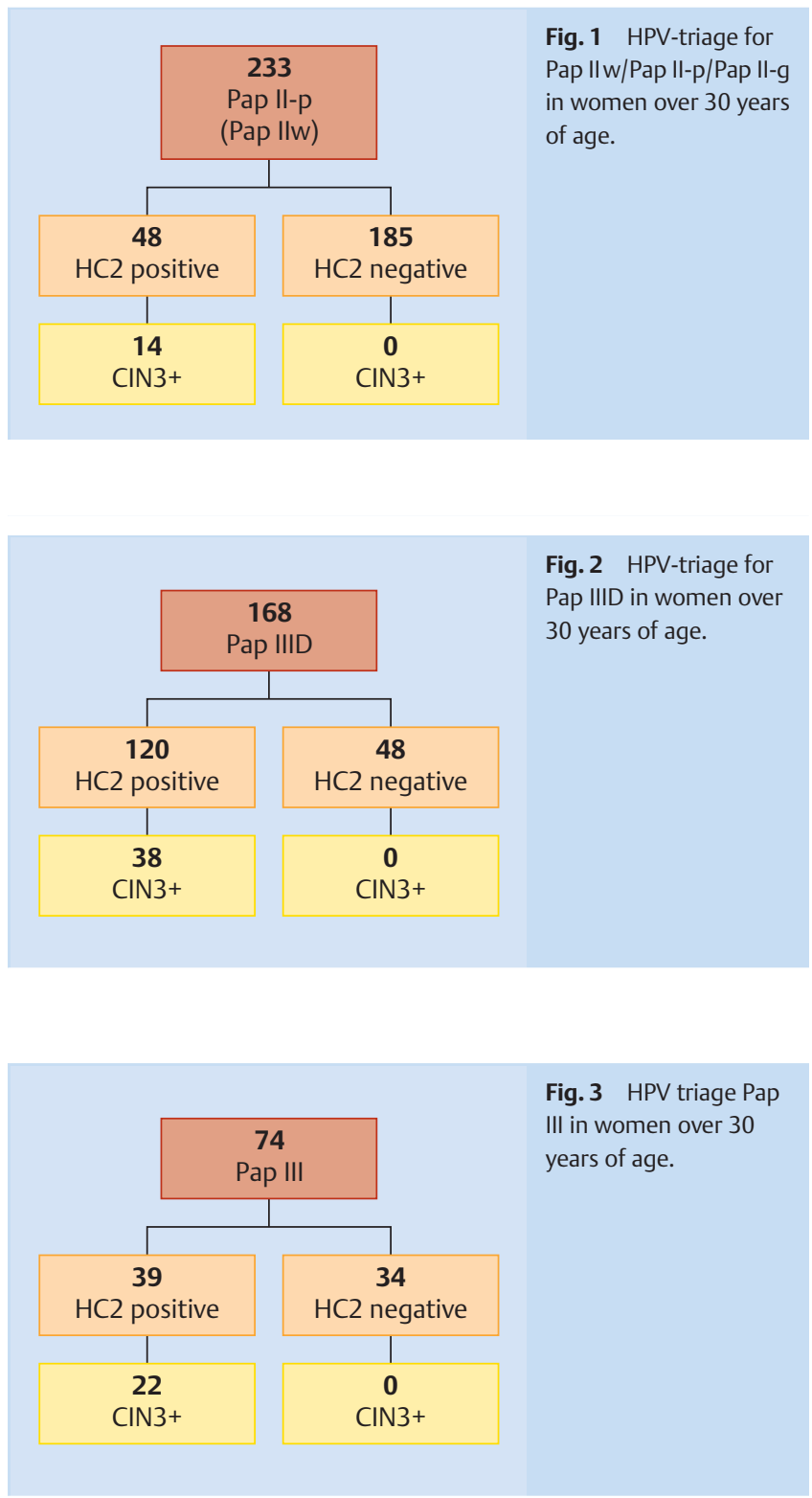

\section{WOLVES/Pap II-p/g}

Among the 20-27 year old WOLVES participants ( $n=1749), 28$ women exhibited Pap II w/II-p/-g findings, 19 of them gave a positive, 9 of them a negative HPV test (31\%). In 5 of the 19 women with HC2, further clarification revealed CIN3 (26.4\%), in contrast only 1 case of CIN1 was detected on further observation of all the HPV negative women.

\section{WOLVES/Pap III and Pap IIID}

Pap III findings were so seldom ( $\mathrm{n}=4$, all HC2-HR positive) that no further analyses were carried out on this group. Pap IIID findings were observed in 35 women. The HC2 test was negative in merely 5 of them (14.3\%), in the further course of all these women the cytology findings were unremarkable and HPV test results remained negative. Of the 30 women with Pap IIID and positive HC2 test merely 3 came down with CIN3. 


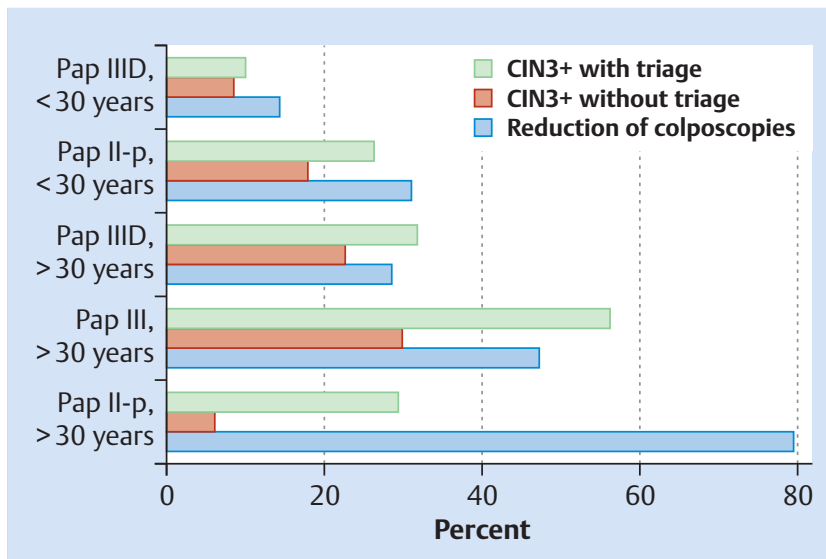

Fig. 4 Effects of HPV triage. Reduction of referrals to colposcopy in HPVnegative cases and demonstration of the general risk for CIN3+ without triage as well as with triage for HPV-positive case.

\section{Discussion}

$\nabla$

Our results demonstrate the very good suitability of HPV screening in the triage for Pap IIw/II-p/-g findings in women over 30 years of age. For HPV-positive women with Pap II-p/-g there is an equally high risk for CIN3+ as for similarly aged women with Pap IIID and positive HC2 (29.2 or, respectively, 31.7\%). In contrast, the rate of CIN 3+ for all participants was merely $6.3 \%$ and thus clearly below the cut-off value of $10 \%$ above which a direct referral to colposcopy is justified ( Fig. 4). The current recommendation in Pap II-p/-g cases to repeat the smear test after one year [13] would have led to a diagnostic delay in 14 CIN3+ cases, on the basis of the data presented here triage by means of HPV screening in the age group of over 30 years appears to be advantageous.

In contrast to the very efficient triage for women with Pap II-p/-g, the CIN3+ rates for Pap IIID of 22.6\% and for Pap III of $29.8 \%$ in women over 30 years of age are clearly above the cut-off value of $10 \%$ and even above the disputed cut-off value of $20 \%$, so that in such cases a direct clarification by colposcopy seems to be justified. The new München III nomenclature was first introduced in 2014 , so that the majority of the cases analysed here are classified according to München II. Unfortunately and especially for Pap IIID findings, we could not always assess whether a Pap IIID1 or a Pap-IIID2 finding had existed according to the new München III classification. On account of the high negative predictive value in the case of a negative HPV test, we thus cannot discount conclusively that an HPV triage for Pap IIID1 findings even so still constitutes a meaningful option, a recommendation for such cases cannot, however, be derived from our result. In general, on the other hand, in the case of Pap III findings in women aged over 30 years an HPV triage may be taken into consideration since the risk for CIN3+ in HPV-negative women is almost completely excluded and the rate of referrals to colposcopy can be reduced by $47 \%$. In this group, however, HPV-independent cancers, especially endometrial cancer, can be excluded with certainty.

In the age group of less than 30 years, the detection of HR-HPV with altogether more than $23 \%$ is very frequent [2] and abnormal cytology findings in the groups III/IIID are associated with HPV in more than $80 \%$. In young women Pap II-p-/-g findings are HPVpositive in more than two-thirds although, in the light of the rel- atively low number of WOLVES participants, we cannot exclude that a more favourable analysis would result in a larger collective and with a focus on the age group 25 to 30 years.

Apart from the not perfect transfer of the Pap IIID findings from the München II to the München III nomenclature, a principally justified point of criticism is that the used procedures differed depending on the HPV status so that possible CIN3+ cases among the HPV-negative women could have been missed. Whereas more than $95 \%$ of the HPV-positive women were referred to colposcopy, the corresponding rate among the HPV-negative patients was only around $10 \%$. Even so, we consider the chance of missing CIN3 in this group to be very low. The compliance of the patients was and is very good; by means of data comparisons with the epidemiological cancer register and the databases of the health insurances, we could exclude cases of CIN3+ diagnosed outside of this study. For more than a third of the HPV-negative women of this study who did not undergo colposcopy (87 of 245 ), long-term courses of more than six years are available, for the remaining cases the follow-up time is shorter but still without any signs of CIN3+.

Besides the HPV screens and repetition of the cytology smear, immunocytochemical dual staining for p16 and Ki-67 is now available as an additional triage procedure for uncertain cytology findings and HPV-positive cases [14-16] and various methylation markers are currently being tested. The p16/Ki-67 detection has been proven in two studies to be equally sensitive for Pap II-p and Pap IIID1 findings as HPV screening is for the detection of CIN2+ cases albeit with a better specificity. On account of the weaknesses of HPV triage in young women and for Pap-IIID findings demonstrated here, it appears that further clarification by means of immunocytochemistry is better suited for such cases.

\section{Conclusions}

In agreement with international studies, it is a fact that also in Germany for women over 30 years of age an efficient triage of low-grade cytology abnormalities in the groups with Pap II-p/-g findings is provided by HR-HPV screening. For HPV-positive cases a referral to expert colposcopy is indicated, for HPV-negative cases, on the other hand, the risk for CIN3+ is minimal. Also in the group with Pap-III findings HPV triage in this age group leads to the definition of a relevant HPV-negative subgroup without a risk for CIN3+ but, however, with a risk for endometrial cancer. In contrast, HPV-HR screening for the triage of Pap-IIID findings in women under 30 years of age appears to be unsuitable since the great majority of such findings is associated with HPV.

\section{Financing}

$\nabla$

WOLPHSCREEN is a pilot project of the Deutsche BKK and Audi BKK in the Wolfsburg region and is sponsored by these insurance companies.

WOLVES is an epidemiological study carried out by Wolfsburg hospital and is mainly financed by Sanofi Pasteur MSD.

WOLPHSCREEN and WOLVES were supported by the Hologic company through the gratis provision of ThinPrep vials. 


\section{Conflict of Interest}

$\nabla$

KUP: Occasional advisor for Roche Diagn. Speaker's honorarium from Roche, Becton Dickinson and Seegene. AL: Speaker's honorarium from Becton Dickinson and Qiagen.

\section{References}

1 Petry KU, Menton S, Menton $M$ et al. Inclusion of HPV testing in routine cervical cancer screening for women above 29 years in Germany: results for 8466 patients. Br J Cancer 2003; 88: 1570-1577

2 Petry KU, Luyten A, Justus A et al. Prevalence of high-risk HPV types and associated genital diseases in women born in 1988/89 or 1983/84-results of WOLVES, a population-based epidemiological study in Wolfsburg, Germany. BMC Infect Dis 2013; 13: 135

3 Petry KU, Rinnau F, Bohmer G et al. Annual Papanicolaou screening for 5 years among human papillomavirus-negative women. BMC Cancer 2013; 13: 379

4 Moss EL, Arbyn M, Dollery E et al. European Federation of Colposcopy quality standards Delphi consultation. Eur J Obstet Gynecol Reprod Biol 2013; 170: 255-258

5 TOMBOLA Group. Biopsy and selective recall compared with immediate large loop excision in management of women with low grade abnormal cervical cytology referred for colposcopy: multicentre randomised controlled trial. BMJ 2009; 339: b2548

6 TOMBOLA Group. Options for managing low grade cervical abnormalities detected at screening: cost effectiveness study. BMJ 2009; 339: b2549

7 TOMBOLA Group. Cytological surveillance compared with immediate referral for colposcopy in management of women with low grade cervical abnormalities: multicentre randomised controlled trial. BMJ 2009; 339: b2546
8 Kitchener HC, Fletcher I, Roberts C et al. The psychosocial impact of human papillomavirus testing in primary cervical screening-a study within a randomized trial. Int J Gynecol Cancer 2008; 18: 743-748

9 Petry KU, Böhmer G, Iftner T et al. Factors associated with an increased risk of prevalent and incident grade III cervical intraepithelial neoplasia and invasive cervical cancer among women with Papanicolaou tests classified as grades I or II cervical intraepithelial neoplasia. Am J Obstet Gynecol 2002; 186: 28-34

10 Solomon D, Schiffman M, Tarone R. Comparison of three management strategies for patients with atypical squamous cells of undetermined significance: baseline results from a randomized trial. J Natl Cancer Inst 2001; 93: 293-299

11 Szarewski A, Ambroisine L, Cadman L et al. Comparison of predictors for high-grade cervical intraepithelial neoplasia in women with abnormal smears. Cancer Epidemiol Biomarkers Prev 2008; 17: 3033-3042

12 Luyten A, Buttmann-Schweiger N, Luyten Ket al. Early detection of CIN3 and cervical cancer during long-term follow-up using HPV/Pap smear co-testing and risk-adapted follow-up in a locally organised screening programme. Int J Cancer 2014; 135: 1408-1416

13 Griesser H, Marquardt K, Jordan B et al. Das Prozedere bei auffälligen Befunden. Kommentar zur Münchner Nomenklatur III. Frauenarzt 2015; 56: 10-13

14 Ikenberg H, Bergeron C, Schmidt D et al. Screening for cervical cancer precursors with p 16/Ki-67 dual-stained cytology: results of the PALMS study. J Natl Cancer Inst 2013; 105: 1550-1557

15 Petry KU, Schmidt D, Scherbring $S$ et al. Triaging Pap cytology negative, HPV positive cervical cancer screening results with p16/Ki-67 Dualstained cytology. Gynecol Oncol 2011; 121: 505-509

16 Schmidt D, Bergeron C, Denton KJ et al. p 16/ki-67 dual-stain cytology in the triage of ASCUS and LSIL Papanicolaou cytology: results from the European equivocal or mildly abnormal Papanicolaou cytology study. Cancer Cytopathol 2011; 119: 158-166 